rev.relac.int.estrateg.segur.6(2):111-138,2011

\title{
APRECIACIONES SOBRE EL CICLO CAFETERO EN COLOMBIA. 1925-2010
}

\author{
José Alberto Pérez Toro. Ph.D*
}

\section{RESUMEN}

Durante el siglo veinte, la economía colombiana ha experimentado una etapa acelerada de crecimiento económico del producto interno bruto del 4,65\%: entre 1906 y el año 2000 se ha multiplicando sesenta y seis veces el nivel del ingreso nacional. El aumento promedio de la población fue del $2.35 \%$ anual, creciendo 8,86 veces, y el ingreso per cápita se acrecentó en 7,45 veces durante noventa y cuatro años. Para el historiador económico estos hechos son motivo de reflexión. Responder acerca de las posibles causas que determinaron este crecimiento y tratar explicar de qué manera el sector externo estimulado durante muchos años por el dinamismo

* El doctor Pérez Toro es Profesor Titular en la Facultad de Ciencias Jurídicas y Políticas en el Programa de Relaciones Internacionales de la Universidad de Bogotá Jorge Tadeo Lozano. Ofrece las asignaturas de Relaciones Económicas Internacionales y de Política Económica de Colombia. Tiene títulos de Ingeniero Industrial en la Universidad de los Andes, Diploma en Desarrollo Económico y M.Phil en Estudios Latinoamericanos en la Universidad de Oxford. Realizó estudios de Doctorado en Ciencias Sociales en UNW en el 2001 y en Historia en la Universidad Nacional de Colombia en el año 2010. Como profesional ha sido funcionario en la Federación Nacional de Cafeteros, Planeación Nacional, Anif, Incomex, Proexpo, y el Ministerio de Comercio Exterior. Por varios años se ha desempeñado en calidad de Profesor Universitario. josea.perezt@utadeo.edu.co 
de las exportaciones cafeteras, es una manera de responder como se impulsó el crecimiento nacional. Con base en el uso de series temporales y el empleo de técnicas que señalan el cambio de pendiente de la curva de crecimiento, se puede identificar de mejor manera los ciclos que inciden en el cambio de tendencia de la misma. Con base en esta ayuda metodológica, se facilitaría el identificar los momentos de cambios en la política económica que actúan como estímulo en el proceso de desarrollo económico. Sobresalen dentro de ellos la adopción de estrategias diseñadas para este propósito, como son las políticas que buscaban integrar territorialmente el país, como por ejemplo: la construcción de la red ferroviaria, fluvial y el avance de vías carreteables, la creación de instituciones bancarias y crediticias, la financiación de bancos de desarrollo y la diversificación de la producción y de los mercados externos; o políticas de penetración de mercados distantes, como una manera de alargar la cadena de valor de la actividad exportadora del país.

Palabras clave: ciclo económico, mercado cafetero, innovación, competencias, cadena de valor, gremio cafetero.

\section{ABSTRACT}

Colombia experienced a rapid rate of economic growth during the twentieth century both in nominal and real terms. Compound rate of $4.65 \%$ of GDP means multiplying growth by sixty six times between 1906 and 2000, while annual population growth rate of $2.35 \%$ means an increase of 8.86 times of this variable. Therefore per capita income improved substantially during ninety four years as this index number increased 7.45 times. Economic historians wonder about these changes as they represent structural transformations. Economic and social causes might be multiple, although coffee industry improvements during one century of modernization explain part of this historical change. Relying on time series analysis and differential calculus techniques, it is possible to establish the occurrences of cyclical behavior of some determinant macroeconomic variables. So the hypothesis we try prove in this paper relates with the set of economic policies adopted by successive governments during most of the twentieth century, that had corrective effect on economic developments on the trade cycle trends. In particular we mention the railway construction that helped integrate productive regions to international trade and the banking system that helped widening the credit system in Colombia. Development banking organizations and policies to diversify exports also contributed to economic growth. Recent microeconomic policies will help the coffee sector participate in the international supply chain, gaining added value to this emblematic national export.

Key Words: economic cycle, coffee market, innovation, competences, supply chain, coffee growers. 


\section{RESUMO}

Durante o século XX, a economia colombiana passou por uma etapa acelerada de crescimento real e sustentável do seu PIB, isto é, 4,65\%: entre 1906 e o ano 2000 o valor da renda nacional multiplicou-se 66 vezes, a média do aumento da população foi de 2,35\% ao ano (reproduzindose 8,86 vezes) e a renda per capita aumentou 7,45 vezes em 94 anos. Para o historiador econômico esses fatos são motivo de reflexão, o que o leva a questionar sobre as possíveis causas que determinaram esse crescimento e tratar de responder de que maneira o setor externo, incentivado durante muitos anos pelo dinamismo das exportações de café, contribuiu para estimular o crescimento nacional. No entanto, baseados no uso de séries temporais e no emprego de técnicas que determinam a mudança da inclinação da curva de crescimento torna-se possível identificar os ciclos que interferem nas variações dessas tendências. Com base neste apoio metodológico, seria mais fácil identificar as mudanças na política econômica que agem como corretivos no processo de desenvolvimento econômico. Destacam-se dentro da adoção de estratégicas para este fim as políticas que procuravam integrar o país territorialmente, tais como: a construção de estradas de ferro e rede fluvial, o avance do sistema rodoviário, a criação de instituições bancárias e creditícias, o financiamento de bancos de desenvolvimento, a diversificação da produção e dos mercados externos ou políticas de penetração de mercados distantes, como uma maneira de estender a cadeia de valor da atividade exportadora do país.

Palavras chave: ciclo econômico, mercado do café, inovação, competências, cadeia de valor, grêmio do café.

\section{INTRODUCCIÓN}

El presente documento titulado "Apreciaciones sobre el Ciclo Cafetero en Colombia. 1925-2010" tiene por objeto poner en perspectiva histórica el comportamiento de la industria el café como un factor que contribuyó al desarrollo económico del país. Dicha actividad se caracteriza por tener una tendencia de largo plazo y presentar unos períodos en que la tasa de crecimiento de los precios mundiales se comporta cíclicamente. Estos ciclos actúan como choques externos que afectan el desempeño de la economía nacional. La particularidad de este enfoque de largo plazo, es que ayuda a comprender el alcance de las políticas públicas adoptadas en cada momento histórico, y sugerir cómo incidieron en el proceso de desarrollo económico nacional.

El estudio que separa los fenómenos de estructura o tendencia del ciclo económico, y los de coyuntura o de cambio, fueron propuestos por el historiador Braudel (1976). Para los historiadores, a diferencia de los economistas, los procesos de largo plazo o de larga duración son los que se refieren a las estructuras. Los tiempos de duración media corresponden a la coyuntura donde se dan los cambios sociales o del desarrollo, y los tiempos cortos o de la visión del individuo, son aquellos donde ocurren los episodios políticos. 
Los aportes empíricos para presentar el modelo citado fueron los proporcionados por el Estudio Greco del Banco de la República, dirigido por Miguel Urrutia (2002), trabajo que presenta los datos sobre estimaciones económicas del país. Con base en los indicadores empíricos se ordena de acuerdo con la metodología señalada y se periodiza los hechos históricos en la misma forma en que lo propone el historiador William A. Green $(1995,1001)$, quien sugiere primero explorar la naturaleza de las fuerzas históricas que propiciaron el cambio, y segundo, ordenar la secuencia en que se dieron los eventos y las políticas que se emplean para enfrentar los hechos económicos a decir por Cipolla en su trabajo "Entre la Historia y la Economía" (1991, 23-25).

\section{APORTES DE LA LITERATURA}

Efectuar un recuento de la bibliografía cafetera que recoja las causas de corto y largo plazo que originaron los cambios económicos es un tema que supera el alcance del presente ensayo. Las obras que se reseñan muestran el efecto del avance del café en el desarrollo económico nacional, aunque se reconoce que su análisis es bastante general. Se destaca que la mayor parte de esta literatura, se refiere a los orígenes de la actividad cafetera, mostrando que antes de convertirse en una industria de alcance nacional, fue un factor de cambio en la economía campesina.

De la revisión historiográfica, la obra más importante escrita sobre la historia del café es el trabajo inédito de Beyer (1947). Las tres primeras secciones de su trabajo "The Colombian Coffee Industry. Origins and Major Trends, 1740-1940", se refieren al desarrollo de la industria del café en Colombia en sus albores, pasando por las historias de los esfuerzos fallidos del tabaco, el cacao, la quina o el índigo. En cuanto al lugar y el tiempo en que ocurrió este cambio histórico, las incursiones de Departamentos como Santander, Cundinamarca y Tolima en el comercio exterior del café, fue una novedad para un país fragmentado por la geografía y la historia. Las ventajas comparativas del comercio cafetero, provinieron de la oportunidad de la geografía nacional que brindó un clima insuperable, una temperatura ambiente y un régimen de lluvias que unidos a la abundancia de los suelos volcánicos, marcó la ventaja comparativa de Colombia en el comercio exterior.

La segunda sección de esta obra inédita para el avance de la historiografía se refiere al "sensacional avance en el proceso de cultivo y los métodos para procesar el grano", al aporte de los factores productivos como son la tierra y el trabajo, y a la disposición para llegar a los mercados externos con un producto de calidad. El autor destaca que en términos de democratización de la producción hubo un gran avance, ya que en 1932 el 87\% de la actividad se desarrollaba en fincas familiares que producían el bien en unidades con menos de 5,000 árboles de café, y el $11 \%$ en terrenos de 5.000 a 20.000 árboles, para el año de 1938, el 22\% del territorio sembrado en el país eran cultivos de café (Beyer, 1947, 290 y 316). 
Parsons (1968) geógrafo e historiador, y su traductor el médico Emilio Robledo, recientemente fallecidos, revelan en la historia económica del país titulada "Antioqueño Colonization in Western Colombia" (1968 y 1997 traducida), los pormenores del cambio estructural ocurrido desde entonces en el país, donde el tema de las migraciones y el otorgamiento de títulos a la propiedad cafetera y campesina han sido aspectos cruciales para la formación del tejido social. El tema del cambio institucional, trabajado por Douglas North, provino del proceso histórico relacionado con el crecimiento demográfico tan caracterizado de Antioquia y otros departamentos, por la colonización en el sur y por la oportunidad de explotar la producción de café suave.

En otros apartes se describe cómo se efectuó la parcelación de tierras mediante la adjudicación de mercedes reales y concesiones de la corona, y luego, de baldíos adjudicados en la época de la República. Demografía, presencia de mineros extranjeros, migraciones, ocupación de tierras baldías y diversificación de la producción de bienes alimentarios, fueron las variables centrales de este modelo de desarrollo (Parsons, 1997, 169-204). Este autor concluye afirmando que las "tendencias particulares del medio antioqueño y el exitoso desarrollo de la exportación de café a gran escala, determinaron la prosperidad de las aventuras industriales".

Koffman (1967) en su importante contribución doctoral de 1967: "The National Federation of Coffee Growers of Colombia", obra inédita, nos embarca en un detallado análisis del auge de la Federación Nacional de Cafeteros y su evolución organizacional. En este trabajo de caso, el autor pormenoriza el aspecto de la asociación de intereses en Colombia en cabeza del gremio de los productores del grano. Destaca la importancia de los cafeteros en la economía nacional y de ahí su interés por agrupar a los productores que se asocian en fincas menores de diez hectáreas, lo que representaba el 95.9\% de las plantaciones (Koffman, 1967,66). Por su parte, Mc Greevey (1971) en la tercera parte de su tesis de doctorado "An Economic History of Colombia" dedica tres capítulos de un total de once, para referirse al tema de la colonización, la agricultura, las exportaciones, el desarrollo económico y el avance en el transporte (1971, 213-214). Esta obra ilustra las condiciones que permitieron alcanzar elevados niveles de competitividad en las fincas y el cómo surgieron los eslabones entre esta actividad y el desarrollo de la industria.

Bergquist $(1973,1981)$ en su trabajo doctoral "Coffee and Conflict in Colombia" destaca las consecuencias políticas de las reformas de la estrategia de Núñez, y su efecto en las etapas iniciales del crecimiento y sobre la institucionalidad del país (Bergquist, 1973, 1). Roger Brew $(1977,2000)$ en "El Desarrollo Económico de Antioquia" ofrece una mirada sectorial, en el que se analiza para la contribución del café a la extensión de la ganadería, y a la colonización de frontera, dentro del proceso de desarrollo económico. La diversificación económica propiciada por la minería, la ganadería, el café, los cultivos de pan coger y la labor del taller artesanal, 
enmarcan el embrión de la productividad total de los factores que dan cuenta del desarrollo sostenible (Brew, 1977, 175).

El trabajo de Bejarano (1987) ofrece una postura refrescante para la academia colombiana frente a los aportes de los investigadores extranjeros. Se titula "Ensayos de Historia Agraria Colombiana", y en su interior resume un pensamiento progresista comprendido en tres ensayos analíticos. Discute el autor en su obra aspectos generales de la problemática social del país, intenta realizar aproximaciones teóricas como las expuestas por Hobsbawm, con la finalidad de explicar la naturaleza de los acontecimientos que inciden en la formación social (Bejarano, 1987, 21-23). En el capítulo sobre los Estudios del Café trata de relacionar el avance del desarrollo con la presencia del capital comercial en la promoción del cultivo durante una primera fase, y en una segunda considera que este recurso abundante fue la fuente de financiación de las exportaciones (Bejarano, 1987, 117-121). Palacios (2002, tercera edición corregida) en su obra El Café en Colombia. 1850-1970. Una Historia Económica, social y Política La obra de Palacios estudia el proceso de introducción de diversas variedades de café en el país y el proceso de legitimación de títulos de la propiedad en regiones con síntomas de violencia campesina (Palacios, 2002, 21-34). Cuellar en su trabajo (2004) "El Crédito Cafetero en Colombia. Economía Instituciones y Política. 1920-2002", despeja un mundo desconocido, en el cual no se conocía bien cuál era el aporte de los productores para financiar las agencias crediticias de propiedad del Gremio. Entidades como el Banco Cafetero, Concasa, Almacafé o el Programa de diversificación Cafetera, influyeron en la formación del ingreso del productor. De esta manera, muestra cómo una parte importante del ingreso cafetero en Colombia proviene de los recursos ahorrados por los productores, en favor del Fondo del Café (2004).

\section{METODOLOGÍA}

\section{HISTORIA Y ECONOMÍA}

El principal problema a superar en esta investigación analítica consistió en proponer un modelo determinístico que permitiera efectuar una periodización de los hechos que caracterizan un proceso histórico de la economía, dependiente del avance de la industria del café y otras actividades sectoriales. Se partió de las propuestas metodológicas reconocidas en el medio académico, como la presentada por el investigador italiano Carlo M. Cipolla, titulada "Entre la Historia y la Economía..." (1991, 21-25). Este trabajo propone orientar el uso de los recursos metodológicos de la economía para entender el pasado en sus propios términos. En este sentido, el término explicación es algo distinto de predicción, que es el uso que los economistas dan a las evidencias como sugieren Blaug (1997) y Friedman (1953), cuando distinguen los propósitos de la economía normativa y predictiva. 
Angus Maddison (1970, 1995, 2002 y 2007) ofrece una metodología para intentar explicaciones del pasado con base en la construcción de series históricas. En Maddison (2002) se compilan evidencias, fruto de una discriminación crítica de la información sobre el crecimiento de la población y el desempeño del ingreso nacional de muchos países del mundo, incluyendo a Colombia. Las cifras del ingreso nacional son fundamentales para entender el problema del crecimiento económico durante muchos años. De esta manera, ajusta los indicadores con la técnica del poder adquisitivo constante, y proporciona datos para Colombia ente 1820 y 1990 (Maddison, 2002, 191). En Maddison (2007, 147 y 149) se proporciona una metodología para trabajar el tema del comportamiento de los ciclos económicos, y comprender el análisis de las tendencias de largo plazo ${ }^{1}$.

Gerschnekron fue quien propuso en "Economic Backwardness in Historical Perspectives" (1962, 5-30), y en "On the Concept of Continuity in History" que existe un sentido histórico en la economía, en el cual pueden ocurrir discontinuidades que marcan el inicio de procesos auspiciosos del desarrollo. El cambio suele hacerse de manera comparada y se observa en el tiempo, con base en la ayuda de indicadores cuantitativos (1968, 13). La forma en que se aproximó al tema de la discontinuidad de la historia la profundiza en el ensayo "Typology of Industrial Development" (1968, 81), cuando observa "el crecimiento de la industria provino del efecto derivado de la transformación en la agricultura, frente al incremento de su productividad. La obra de este historiador económico es importante para el análisis del desarrollo porque propone que con el uso de la narrativa histórica se pueden efectuar comparaciones sobre explicaciones efectuadas por distintas escuelas o modelos, sin entrar a refutarlas o contradecirlas. También, para desentrañar la naturaleza de las crisis y los cambios que determinan oportunidades o tendencias nuevas de los hechos.

Para el caso de Colombia, nos sirve su enfoque porque nos indica cómo la industrialización, que comenzó con la creación de empresas pequeñas orientadas a la producción de artículos de consumo, avanzó a otra etapa con la importación de maquinaria e insumos, y con la ayuda de la protección que brindaron los aranceles al expedirse la Ley 62 de 1931.

1. Maddison muestra al descomponer las series de tiempo que la economía internacional se caracterizaba por registrar ciclos económicos largos de 50 años, unos medianos de 7 y 10 años, y otros que denominó como cortos de 3 y 4 años. Eliminando del ciclo, el efecto de la tendencia, encontró unos movimientos que denominó como secundarios, con promedios móviles de nueve años, con lo cual extrajo el efecto de la influencia de los ciclos más cortos en la tendencia del largo plazo. Calculó con base en este modelo el comportamiento de los salarios, tipos de interés, valor del comercio exterior y depósitos bancarios. Distinguió con su modelo las fases de ascenso y descenso, y en cada honda o ciclo mostró la amplitud de estos. Uso en su análisis varias técnicas para eliminar del modelo el efecto de la tendencia cómo el de los efectos rezagados. Para un análisis detallado sobre este tópico histórico y de la internacionalización definitiva del país, ver Angus Maddison. "Fluctuations in the Momentum of Growth Within the Capitalist Epoch". Cliometrica. 2007. Vol 1. Págs, 145-175. 
Al respecto Ospina sugiere:

- Que pocas industrias se dieron como un despertar repentino o "great spurt".

- Que la industrialización como proceso fue un medio importante para transformar la producción y modernizar las sociedades.

- Que en Colombia florecieron las industrias de los textiles y confecciones y luego de la fundición, al ir avanzando en la producción de bienes manufacturados sencillos y verse estimulados por el aporte de los sectores complementarios. (Ospina Vásquez, 1974, 544).

\section{ECONOMÍA DEL DESARROLLO}

Dentro de los estudiosos referidos sobre el tema de América Latina y su desarrollo, el autor Beyer (1947, xi-xii) es quien define a la actividad cafetera nacional como una industria, en virtud de su comportamiento microeconómico, caracterizado por tener una función de producción, susceptible de aumentar su productividad a través del manejo racional de los insumos y los factores que determinan su producción. En el ámbito macroeconómico y del crecimiento, su aporte se manifiesta por el monto del valor agregado que genera, el volumen de empleo que vincula el sector, el monto de divisas que produce a nivel agregado, y en el medio del desarrollo económico por las externalidades y complementariedades que genera. El café es considerado como industria por su alta capacidad de generar fuentes de empleo productivo en el sector tradicional, tanto empleo directo como indirecto, y por la fuerte relación de intercambio que se produce entre los sectores productivos de alimentos y de productos manufacturados de consumo.

La visión de los microeconomistas sobre la industria del café sugiere que de su expansión y prosperidad a nivel de las unidades productivas individuales, se irrigan un número creciente de vínculos que integran la actividad de la producción-distribución a nivel nacional. Es en estas fases de la producción y el intercambio, que se generan crecientes cantidades de valor que se adiciona a la industria a lo largo de la cadena producción-distribución, a decir por Porter (1995, 51-57).

La mayoría de los modelos que recoge la literatura sobre los desarrollos y efectos de la economía del café se refieren a momentos o instantes en que los actores tomaron la decisión de invertir en las fincas productoras de café, de modificar las situaciones de pertenencia de los cultivos o las relaciones entre propietarios y trabajadores vinculados a la industria de exportación. Se pudo apreciar que suele ser menos copiosa la literatura que se refiere al afecto agregado de invertir en 
la industria cafetera, y que indague sobre las consideraciones y aportes de esta industria, que en el agregado, contribuyen a acelerar el crecimiento económico.

El modelo de Chenery $(1968,646)$ pensado para explicar el efecto del comercio en el crecimiento de largo plazo, sugiere que en la medida en que se agrega mano de obra calificada a la economía, se dispone de fuentes de ahorro para apoyar la inversión y se proporciona un flujo creciente de importaciones, incluyendo las materias primas y los bienes de capital. Y es así como se pueden mejorar las condiciones para crecer en el largo plazo (Maizels, 1971, 8-9). En otros aportes de la obra de Maizels, se destaca el criterio de la elasticidad de la inversión como un tema que se asocia con la capacidad de multiplicar la capacidad de invertir en activos representados por capital fijo. De esta manera, se multiplica la capacidad de incrementar el producto, el nivel de beneficios fruto de las exportaciones y se aprovecha mejor el efecto del incremento en el flujo de capital extranjero (Maizels, 1971, 18-19).

Establecer de qué manera la actividad del comercio exterior aporta en el crecimiento económico de una economía, es un tema del desarrollo que se apoya en el análisis empírico. Sus resultados ayudan a construir el método histórico comparativo, lo que permite diferenciar cómo en los países en desarrollo el sector productor de bienes agrícolas es el que genera la mayor parte de los excedentes para la exportación. También, enunciar que el efecto de las externalidades positivas de producción y las complementariedades muestran su mayor potencialidad para explicar las causas del crecimiento (Klenow y Rodríguez-Clare, 2005, 819-825).

El aporte del comercio en el desarrollo lo muestra Lewer y Van den Berg en la obra "How Large is International Trade's Effect on Economic Growth?". Allí, estos autores encuentran que sobre un conjunto de 100 regresiones simples de países con ingresos per cápita medio, el coeficiente de la ecuación que relaciona el comercio con el producto revela que su contribución o aporte es del orden del 20\%. Sobre un total de 402 ecuaciones de regresión simple ordenadas de distintas maneras, concluyen que por cada aumento de una unidad en el producto, el 0,22 del incremento está determinado por el crecimiento del comercio (2003, 368-372).

\section{FORMULACIÓN DEL MODELO}

Hechas las precisiones anteriores, se trató de identificar empíricamente los grandes momentos de cambio suscitados con la evolución de los mercados, y por efecto de las acciones de política económica. Los cambios de la economía durante un siglo se caracterizan primero por ser de largo plazo o "de larga duración" como sugieren Braudel (1976), y Gemelli (2005). En segundo lugar, se encontró que si se separan estos momentos de la línea de tendencia, en las series del Producto Interno Bruto y su tasa anual de crecimiento, o en la evolución de los precios internacionales reales del café, existe un comportamiento cíclico. De esta manera: 
1. Como modelo se emplea la relación Logaritmo Natural (Año i+1/Año i), cuya igualdad muestra cuál es la tasa de crecimiento real del indicador año por año. La virtud de esta metodología consiste en que permite estimar la tasa de crecimiento real para uno o varios años, al dividir la suma de las tasas de crecimiento real del periodo por el número de años del periodo. De esta forma, se puede emplear las metodologías del promedio móvil de las tasas de crecimiento o "primera derivada" de la línea de tendencia, y establecer que aparecen seis períodos o fases de crecimiento que determinan el comportamiento cíclico del crecimiento real de la economía entre 1905 y 2006. Con base en la metodología de los rezagos, se establece que al suavizar la serie del PIB real con base en el criterio de un polinomio de sexto grado, se destacan "tres grandes ciclos" tipo Kondratieff "de largo plazo".

2. Con base en las cifras del punto anterior se reagrupan las tasas de crecimiento en los seis periodos escogidos, y con base en el modelo "staked-line" del programa Excel de Office, se aprecia el comportamiento cíclico de la economía. Para obtener los resultados se toman los precios nominales del café para el año calendario, y el tipo de cambio promedio del año calendario. Se descuenta el valor de la tasa de cambio nominal con base en el IPC de Estados Unidos con base en el año 1925=1, y se procede así a calcular el nivel de la tasa de cambio real y el precio real del café.

3. La Gráfica No. 1 muestra el comportamiento del producto interno bruto entre los años 1905 y 2005. Se ilustra la tasa de crecimiento anual tomada del Ln (Año2/Año1), y se aplica la técnica de los rezagos con seis promedios móviles, con lo cual se identifican seis fases de crecimiento durante el periodo. Si se adopta el criterio de ajustar los datos con un polinomio de sexto grado o cinco efectos rezagados, se obtiene una onda de tres grandes ciclos.

4. La Grafica No. 2 muestra el comportamiento de los seis ciclos del producto durante el siglo. Al superponer las tasas se evidencia el comportamiento cíclico de la economía.

5. Las Gráficas No. 3 y No. 4 ubican en el plano cartesiano los precios nominales y reales del café durante un siglo. Se aprecia la tendencia de los precios y las denominadas bonanzas. Al superponer lo precios reales en tres grandes segmentos de treinta y tres años aproximadamente, se distinguen tres grandes ciclos o fases de la economía cafetera, donde los precios tuvieron tres fases de precios ascendentes y tres descendientes.

6. A simple vista en el Gráfico No. 5, se puede observar la relación existente entre la Tasa de crecimiento del PIB y la Tasa de crecimiento del Precio del Café, en este caso entre los años de 1946 y el 2000. Puestas las series en planos superpuestos, es evidente el grado de correlación entre el crecimiento del producto y los precios del café. 


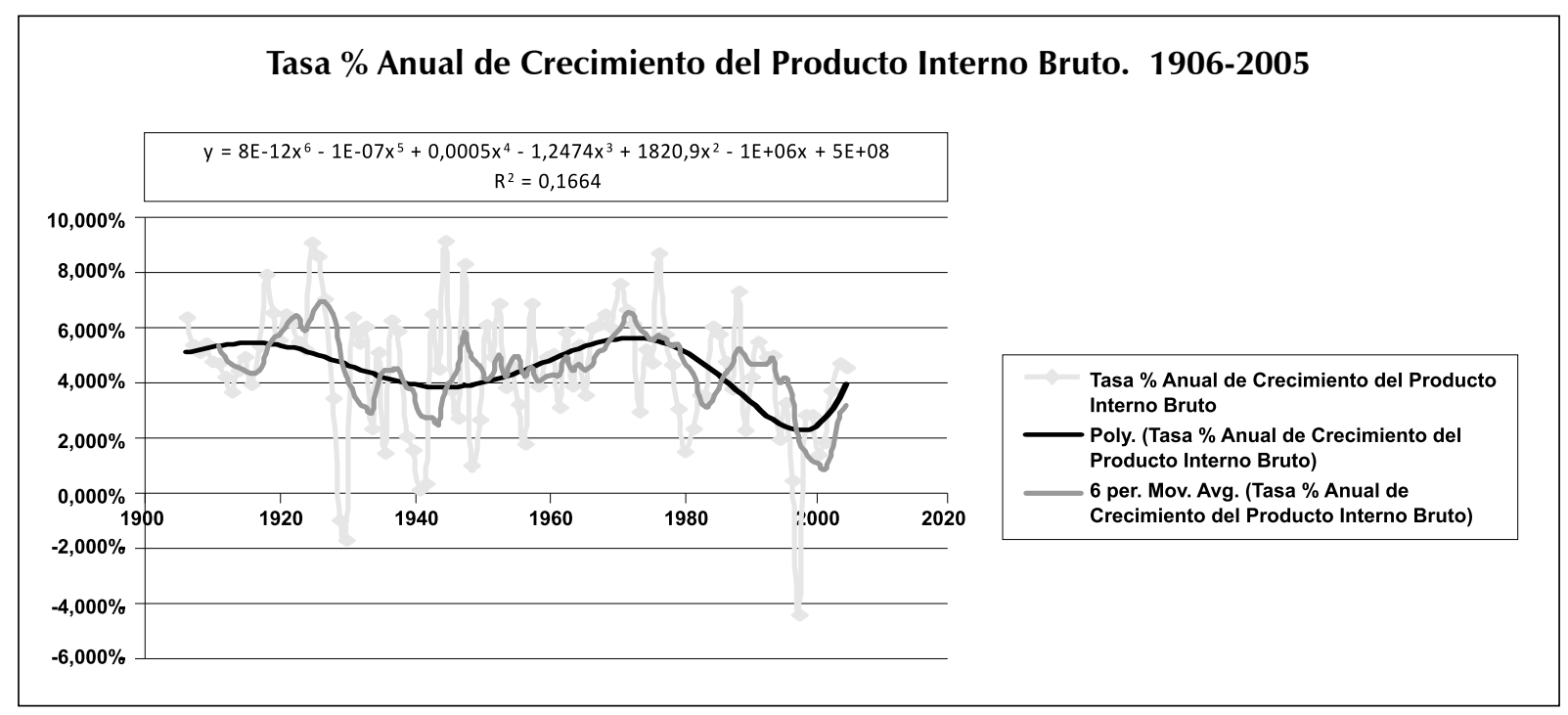

Gráfica No. 1: Tasa de Crecimiento del PIB en la Economía Colombiana, Ciclos y Fases del crecimiento. 1905-2005

Fuente: Greco. Banco de la República. 2002. El Crecimiento Económico Colombiano en el Siglo XX. Director Miguel Urrutia Montoya. Fondo de Cultura Económica. Bogotá. PIB real y deflactor implícito Empalme GRECO-CEPAL-DANE(SCN7 68) Año base 1975 Millones de pesos (1). PIB real GRECO Ajustado al SCN 93 Año base 1975 Millones de pesos (2). PIB corriente GRECO Ajustado al SCN 93 Millones de pesos (3). Deflactor PIB GRECO Ajustado al SCN 93 Año base 1975* (4).Deflactor PIB GRECO Ajustado al SCN 93 Año base 1994 (5). PIB real GRECO Año base 1994 (6). Tasa de Crecimiento del PIB - GRECO Base 1994=100. Cálculos del Autor para medir el comportamiento de la tasa de crecimiento real, del productor real de año a año, o de período a período.

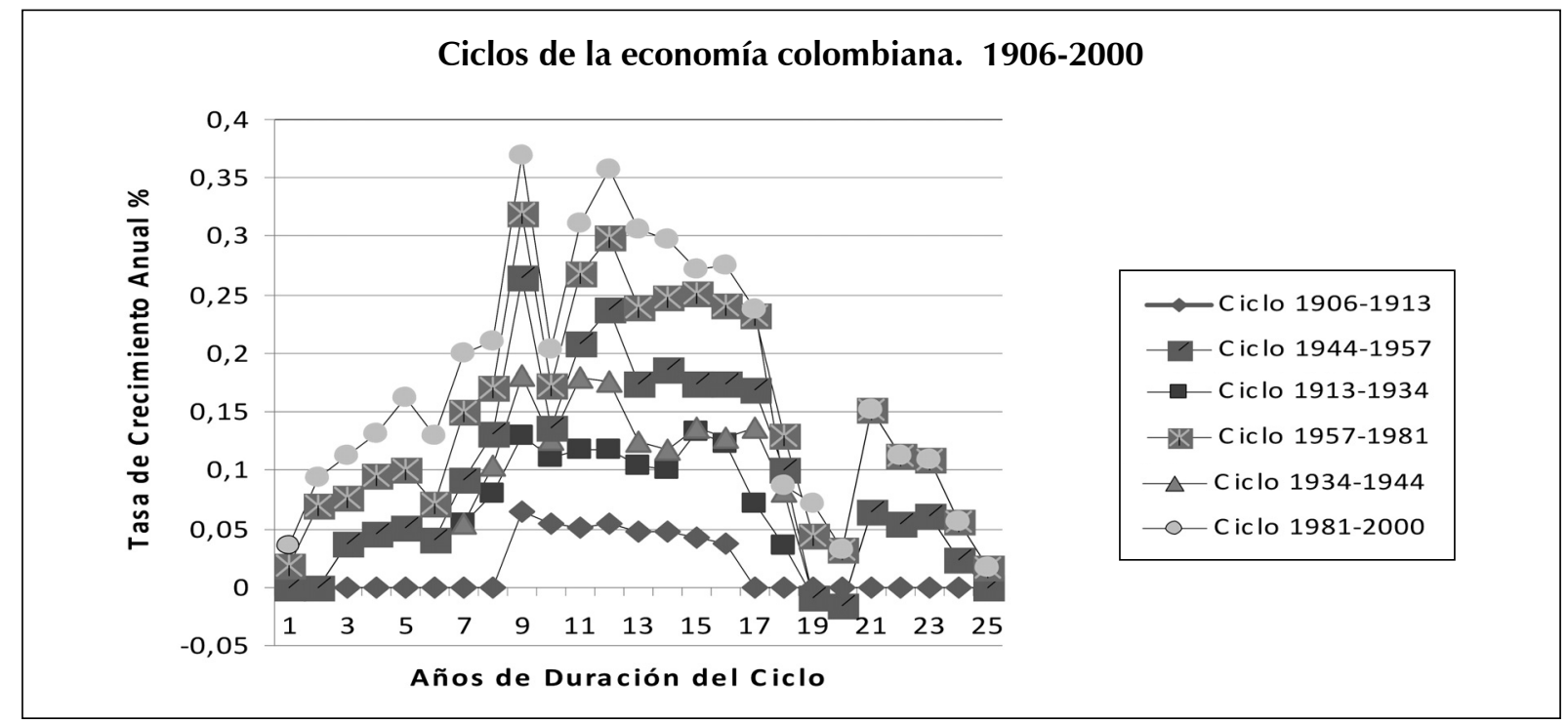

Gráfica No. 2: Comportamiento Cíclico del Crecimiento del Producto

Fuente: Con base en las cifras del Cuadro Anterior se reagrupan las tasas de crecimiento en los seis períodos escogidos, y con base en el modelo "stakedline" del programa Excel de Office se aprecia el comportamiento cíclico de la economía. El autor Alexander Gerschenkron. En sus obras Gerschenkron (1962 y 1968), en los Capítulos Economic Backwardness in Historical Perspectives, Pág 5-30 de la primera obra, y en la siguiente obra en el Capítulo "On the Concept of Continuity in History", (Págs 11-39) analiza el alcance de las discontinuidades en el evento histórico en la manera de pensar la historia y el desarrollo económico (Pág 15). 


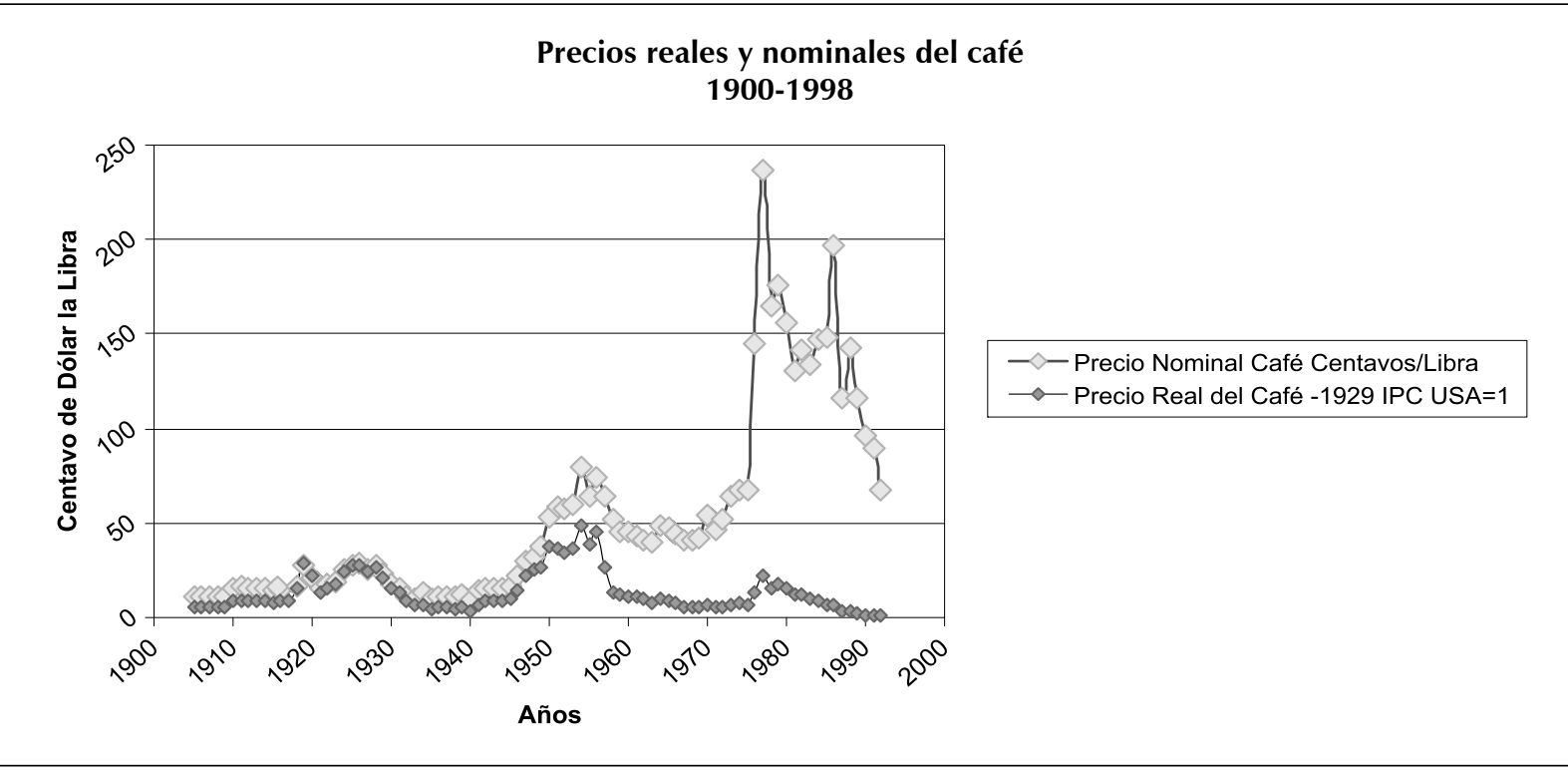

Gráfica No. 3: Comportamiento Cíclico del Mercado Cafetero y su Relación con el PIB Nacional

Fuente: Miguel Urrutia. Greco. Banco de la República. 2002. El Crecimiento Económico Colombiano en el Siglo XX. Fondo de Cultura Económica. Bogotá. Tablas VII 3.1. A y VII. 3.3.A. Metodología. Se toman los precios nominales del café para el año calendario, y el tipo de cambio promedio del año calendario. Se descuenta el valor de la tasa de cambio nominal con base en el IPC Estados Unidos con base en el año 1925=1. Se calcula así la tasa de cambio real y el precio real del café.

\section{Ciclos del Café a Precios Constantes de 1925}

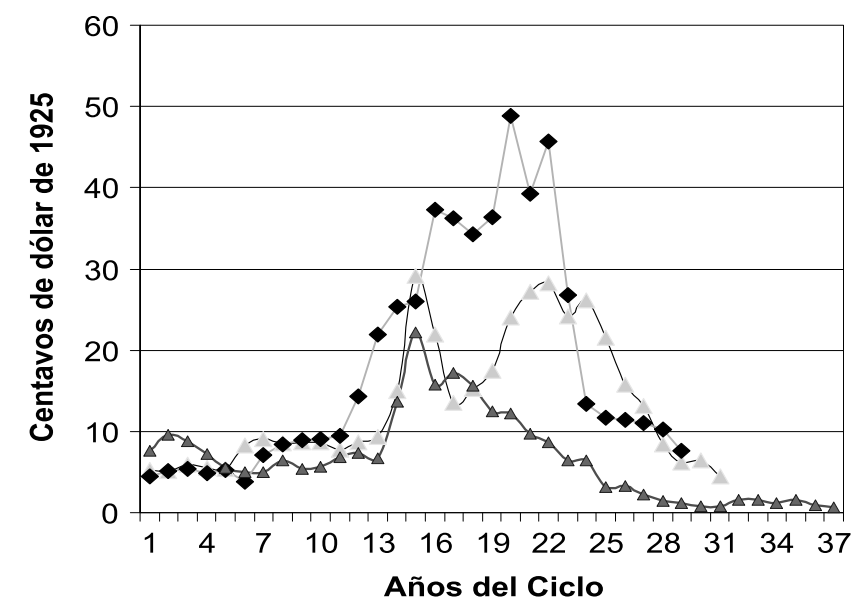

Gráfica No. 4: Ciclos de Precios de los Precios Mundiales del Café. 1905-2000.

Fuente: Con base en las cifras del Gráfico No 4, se analizan las cifras de la tasa de crecimiento real de los precios históricos anuales del café del año calendario, y al reagruparlas en tres conjuntos de unos treinta y tres años, se evidencian tres grandes comportamientos cíclicos de los precios reales del café en el mundo. 


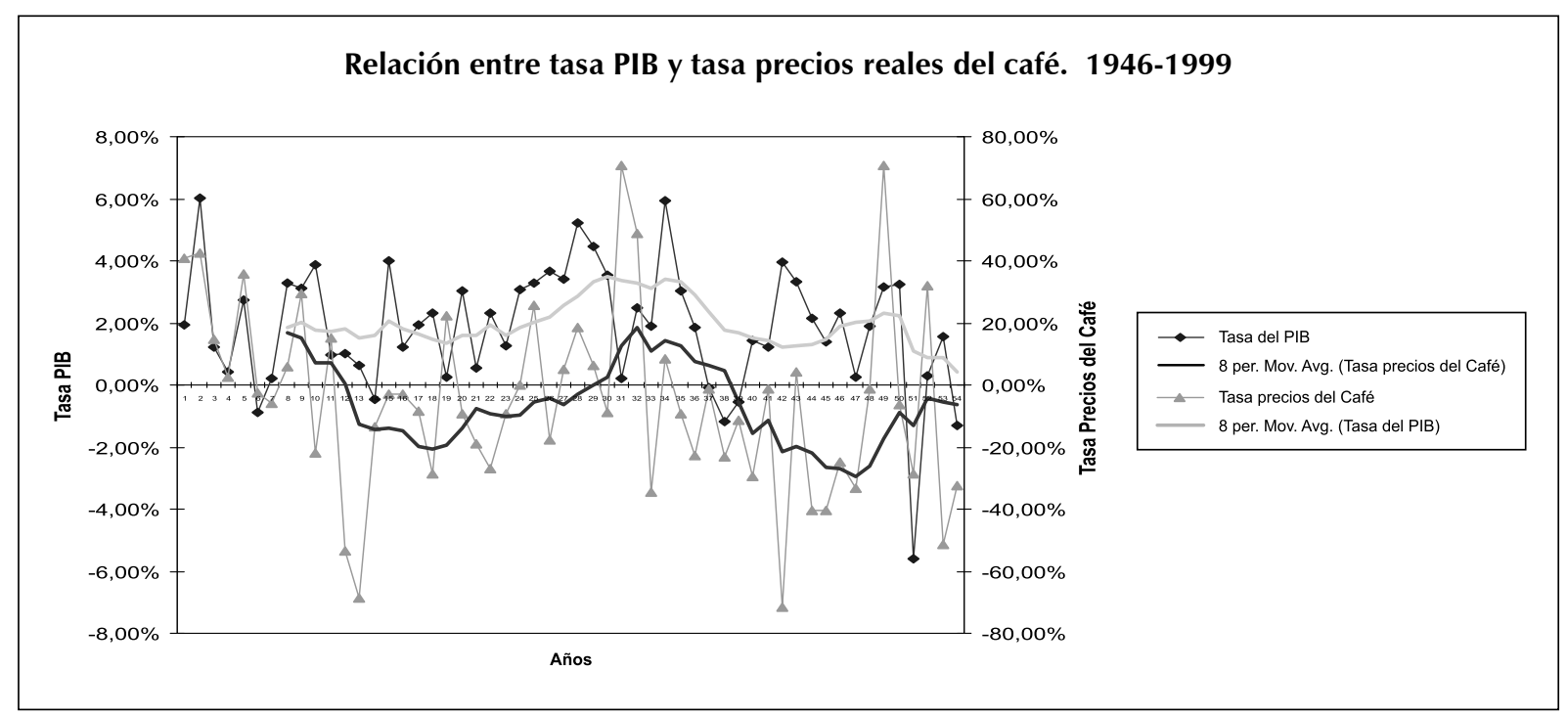

Gráfica No. 5: Relación entre la Tasa del PIB y Tasa del Precio del Café. 1946-2000

Fuente: Greco. Banco de la República. 2002. El Crecimiento Económico Colombiano en el Siglo XX. Director Miguel Urrutia Montoya. Fondo de Cultura Económica. Bogotá. Deflactor PIB GRECO Ajustado al SCN 93 Año base 1994.B36. Deflactor PIB GRECO Ajustado al SCN 93 Año base 1994 (5). Esta serie se obtiene de dos maneras: dividiendo (3) por (5), o retrapolando desde 1994 a 1905 el valor del PIB de 1994 del SCN 93 con las tasas de crecimiento de (2); de 1994 a 2000 son los valores de DANE estimados con la nueva base. Cálculos del Autor.

\section{INTERPRETACIÓN DE LA ENCUESTA HISTÓRICA}

\section{PRIMER CICLO. 1906-1940.}

Primera Fase 1906-1929.

Terminada la Guerra de los Mil Días, el país atravesaba una inesperada crisis económica. Los precios mundiales del café habían declinado de 17,1 centavos de dólar la libra en 1889, a 7 centavos en 1901. Gradualmente, los precios se elevaron hasta 15,6 centavos en 1914, y los ingresos externos se recuperaron de US\$3,19 millones de dólares en 1901, a US\$18,56 millones de dólares en 1914. En el año de 1919, el café representaba el 68.7\% del total exportado por el país (Lleras de la Fuente, 1970, Cuadro No 6. Beyer, 1947, Apéndice Cuadros I y IV. Harbison, 1976, 30).

Durante estos años, la expansión de la población fue muy grande, así como el número de haciendas vinculadas a la actividad cafetera en Cundinamarca y Tolima. En Antioquia, la estructura de la propiedad era diferente ya que el número de fincas familiares creció considerablemente desde finales del siglo XIX. En el año de 1918 se estimó que el número de fincas en producción ascendía a 4.500 en este Departamento, y hacia 1927 el número de parcelas se calculó en 11.439. En la mayoría de los casos, no tenían más de un millar de cafetos en producción (López. 1927, 259) 
Al comienzo de esta primera fase, el café se manifestó con sus choques externos en el resto de la economía, este evento histórico suscitó una transición social y económica inédita. Dentro de los cambios institucionales ocurridos por la expansión de las reservas de divisas generadas por el café, surgió la necesidad de organizar las finanzas, siendo necesario crear el Banco Central, el cual asumió funciones crediticias y de regulación monetaria. Gradualmente, se avanzó en la propuesta de integrar al país dentro del sistema monetario internacional regulado por el patón oro, abriéndose el mercado a los créditos internacionales.

El ingreso promedio de US\$ 8 millones de dólares anuales generados por el sector externo durante la década 1900-10 significó una multiplicación del sector externo alrededor de once veces. Durante el período 1923-29, el valor total de los ingresos de divisas se elevó a US\$ 752.8 millones de dólares al mismo tiempo que las cafeteras sumaron US\$ 526.3 millones en exportaciones, y otros US\$190.5 millones representados por los productos de banano y petróleo, entre otros. El valor exportado de petróleo fue de US\$ 84.4 millones durante el período 1923-29, seguido en orden de importancia por el banano, bien básico que contabilizó US\$ 42.2 millones de dólares ${ }^{2}$. Entre 1920 y 1928 el valor de los recursos externos recibidos evolucionó desde US\$ 36.4 millones de dólares hasta US\$88.2 millones anuales, es decir, hubo un incremento en el nivel de ingresos de casi dos y medio veces en este corto periodo. Una importante fuente de ingresos provino de la indemnización por la pérdida de Panamá, cuya suma ascendió a US\$ 25 millones. Estos recursos recibidos al inicio de la década de los años veinte, sirvieron para avanzar en la extensión de la red ferroviaria (ver Tabla No. 1)

Tabla No.1: Asignación de los recursos de la indemnización por la pérdida de Panamá

\begin{tabular}{|l|l|}
\hline \multicolumn{1}{|c|}{ Líneas } & \multicolumn{1}{c|}{ Valor } \\
\hline Línea Puerto Wilches-Bucaramanga & US\$3.2 Millones \\
\hline Ferrocarril de Nariño (Tumaco-Pasto) & US\$2.4 Millones \\
\hline Ferrocarril del Carare & US\$2.0 Millones \\
\hline Ferrocarril del Norte & US\$3.2 Millones \\
\hline Ferrocarril del Pacífico (Buenaventura-Cali) & US\$4.6 Millones \\
\hline Ferrocarril de Antioquia & US\$1.2 Millones \\
\hline Ferrocarril de Caldas & US\$0.8 Millones \\
\hline Ferrocarril de Bolívar & US\$2.0 Millones \\
\hline Ferrocarril del Sur & US\$0.6 Millones \\
\hline SUBTOTAL & US\$20.0 Millones \\
\hline Financiación del Banco de la República & US\$5.0 Millones \\
\hline TOTAL & US\$25.0 Millones \\
\hline
\end{tabular}

Fuente: P.R.O. Lee, C.C.A., pág. 14. 
También fue importante el aumento de la inversión directa norteamericana, que en forma acumulada aumentó de US\$ 4 millones en 1913, a US\$ 230 millones al finalizar la década de los años veinte. En sólo préstamos sindicados, hasta el año de 1928, se habían efectuado desembolsos por valor de US\$170 millones, en tanto que para el año de 1930 en lo que respecta al petróleo, la inversión directa había superado los US\$ 45 millones (Rippy, 1970, 12). De todos estos recursos, se invirtieron un gran total de US\$ 209 millones de dólares en la ampliación de la red ferroviaria y en el soporte de la naciente red vial nacional, lo que permitió poner en funcionamiento nuevos puertos y varias rutas terrestres.

Fruto del auge económico y de la necesidad de contar con nuevas instituciones, se modernizó el sistema bancario y crediticio, con la creación del Banco de la República, la Contraloría, varios Bancos Especializados en Hipotecas y Agricultura. También se fundó la Bolsa de Bogotá. El autor Torres García mostró cómo en la medida en que la economía entró en una fase de crecimiento sostenido, y los ingresos por concepto de las exportaciones mejoraron, el sector financiero del país se pudo organizar para mantener una relación equilibrada entre los medios de pago en circulación y el volumen de reservas que respaldaban la moneda. Así, al crecer la oferta monetaria, el ritmo al que se expandía la economía nacional permitía irrigar con sus disponibilidades financieras las necesidades crediticias más auspiciosas para el desarrollo. Indicaba el autor, cómo debido al fortalecimiento del sistema financiero:

La producción industrial mejoró gracias a los estímulos proporcionados por el incremento en la demanda interna, cuyo origen ha sido el aumento generalizado por el poder de compra de los cafetero y otros consumidores. La facilidad crediticia originada en parte en la abundancia de la oferta monetaria, ha estimulado la importación de bienes de capital, perfilándose la posibilidad de proporcionar una mayor producción de bienes de consumo para atender las necesidades del mercado doméstico. La abundancia de capital ha contribuido a que ciertas actividades que tienen un alto grado de riesgo como la minería, se hayan estimulado...y la actividad agropecuaria se haya diversificado (Torres García, 1945, 226).

Grandes cambios históricos se aprecian de las cifras estudiadas, dentro de las que sobresale la evolución de la estructura de la propiedad agraria, como lo confirmó el censo de 1928, en el que se muestra que existían en el país más de 500.000 propietarios cafeteros ubicados en veinte departamentos. El efecto del cambio en la producción de café permitió crear una base económica de mercado asentada en el incremento de la demanda. El café y su demanda por productos

2. Ver P.R.O. FO 371 - 16570 -369 / A 28 / 11. Annual Report 1932. Dickson to Sir John Simon, p. 35. Beyer, R.C. Transportation and the Coffee Industry, p. 23.Anales de Economía Estadística. República de Colombia. Tomo III No. 2, abril 1949, p.19. 
alimenticios de vestuario y otras necesidades básicas, permitió apoyar la agricultura moderna, conectar la red vial nacional con los ferrocarriles, puertos y nuevas carreteras, atendiendo con este sistema de comunicación el mercado externo. La demanda de los cafeteros y la mayor población del país permitieron registrar la aparición de las primeras industrias de producción masiva.

Segunda Fase. Crisis de 1929-1940.

Para enfrentar la crisis originada en el Crack de la Bolsa de Nueva York en 1929, el gobierno firmó diecisiete proyectos de ley, incluyendo aquel instrumento propuesto por la Misión Kemmerer para conjurar la crisis financiera. Se aprobaron por ejemplo, nuevos impuestos municipales y la codificación a los impuestos de herencia, y se suspendieron las ayudas a los programas de obras públicas ${ }^{3}$. Se suprimieron subsidios a las obras públicas, sobre la base de que esas ayudas permitían elevar el nivel de empleo.

Se le otorgó la facultad al gobierno de preparar un Presupuesto Nacional equilibrado, y llevar una cuenta de los recursos disponibles para cumplir con los compromisos del endeudamiento externo, en virtud de que el país se había excedido en su capacidad crediticia, por invertir en obras de infraestructura que abarcaban el territorio andino del país. Se le autorizó también al gobierno, regular los giros en moneda extranjera a los residentes en el exterior, e impedir operaciones que vulneraran las reservas internacionales. También, se limitó la libertad de remitir al exterior el exceso de las ganancias en industrias como petrolera y la bananera ${ }^{4}$.

En materia financiera, uno de los primeros pasos que dio el gobierno para responder al efecto de la Depresión, fue atender con los recursos de las reservas, US \$31 millones, de dólares para cubrir las obras de infraestructura detenidas por efectos de la crisis. Se propuso la emisión de los bonos para financiar los ferrocarriles y atender deudas departamentales por valor de US $\$ 6$ millones, de dólares dando un plazo de cinco años, y a una tasa de interés del $8 \%$ anual. Posteriormente, se firmó un nuevo acuerdo con un grupo de banqueros en Nueva York, que llegó al extremo de ofrecer financiamiento al $10 \%$ al gobierno para desembolsar recursos por valor de US \$20 millones 5 .

En la medida en que los efectos de la Depresión se profundizaron, las compañías de transporte fluvial abandonaron sus operaciones y enfrentaron una dramática declinación de la carga, situación que llevó a la bancarrota a las compañías navieras, reduciéndose en número de veintiocho a nueve. Sólo dos de las sobrevivientes llegaron a controlar la mitad de la carga años más tarde como sugiere Barnhart (1953, 21).

3. P.R.O. FO-361-15086 y Mensaje Presidencial al Congreso. 20 de julio de 1931.

4. P.R.O. FO-361-15832-369 / A4233 / 18 / 11, P.R.O. FO 361- 16513-366/ A495 / 1068 / 11. Reporte Anual de Colombia 1932. De Dickson a Sir John Simon, pág. 14

5. P.R.O. FO- 361-15083 / A16 / 11. 
El conflicto con el Perú permitió al gobierno avivar un fuerte sentimiento patriótico. Las cláusulas del Tratado Salomón-Lozano le adicionaban al Perú el área del banco sur del río Putumayo, encerrando geográficamente cada vez más al Ecuador, mientras que a Colombia se le cedía el trapecio amazónico. El Ministro de las Finanzas, Esteban Jaramillo tramitó en el Congreso la Ley 12 de 1932, mediante la cual se autorizaba al gobierno a obtener un préstamo patriótico por $\$ 10$ millones de pesos. De esta forma, se trataba de vincular el ahorro privado para conjurar la crisis del Estado, y con la entrega patriótica de oro, joyas y otros activos de valor, se respaldó la emisión de bonos públicos. Fue así como las reservas de oro se pudieron incrementar en poco más de un millón de pesos ${ }^{6}$. La reactivación se logró no solo mediante el otorgamiento de créditos, sino con la financiación y la creación de nuevos organismos crediticios. Con el Préstamo Patriótico de 1932 se promovió la capitalización del Banco Central Hipotecario y de la Caja de Crédito Agrario. El gobierno terminó apoyando la situación de la deuda departamental y municipal, que ascendía a $\$ 200$ millones y $\$ 43$ millones respectivamente ${ }^{7}$. Cuando se creó el Banco Central Hipotecario, el Banco de la República contribuyó con una suscripción de \$19 millones, y el público suscriptor y los bancos comerciales con otros diez millones de pesos (Franco Hoguín, 1966,83-84). El Banco inició operaciones tan pronto suscribió \$12.5 millones, cifra que se asignó muy pronto, por cuanto la banca comercial tuvo que transferir el $20 \%$ de su capital y de su reserva legal para cubrir dicha promesa (Torres García, 1945, 403). La asignación de recursos para estimular la reactivación económica fue muy efectiva, pues durante los primeros seis meses de operaciones efectuó 164 préstamos por un valor de dos millones de pesos.

Con el objeto de financiar la actividad de las manufacturas y comenzar una fase de crecimiento hacia adentro, al adentrarse la crisis, el país descubrió que con la ayuda del café y el buen crédito, había incrementado su capacidad instalada en la industria. Hacia 1933 se había invertido \$880.000 para incrementar la producción, y un año más tarde, se hizo una reinversión de capital accionario por un millón de pesos. En 1937 se efectuó un nuevo ensanche en el sector fabril por valor de \$1.2 millones. Durante el período comprendido entre los años de 1931 y 1939, el segmento del sector externo que tuvo cambios en su composición fue el de las importaciones de bienes de capital (Gómez Martínez, 1945, 48 y Echavarría, 1943, 37).

\section{SEGUNDO CICLO. 1940-1959}

Primera Fase de la Guerra.1940-1945

La obra David de Bushnell "Eduardo Santos y la Política del Buen Vecino" nos permite apreciar que el período de la guerra se caracteriza por una buena posición financiera del país y una limitación de las importaciones por efecto de las restricciones impuestas por la Guerra. Durante este periodo, se avanza en la construcción de una red de carreteras nacionales que tiene por

6. P.R.O. FO 361- 16513-366/ A495 / 1068 / 11. Reporte Anual de Colombia 1932. De Dickson a Sir John Simon.

7. P.R.O. FO- 371-15831/A36/18/11. 
objeto integrar las regiones nacionales entre sí. A lo largo de esta fase se manifiesta una creciente presencia del Estado, reflejado en el continuo avance de las obras públicas, como fueron las carreteras, acueductos y alcantarillados, y se evidenció el apoyo a la industrialización, empleando como herramienta los elementos diferenciadores del arancel, o las listas de prohibida importación. La injerencia del Estado en el modelo macroeconómico tenía la intención de preservar el equilibrio de los precios relativos y el ordenamiento del crédito, como una manera para evitar presiones sobre la balanza de pagos, en virtud del aumento de la liquidez que suscitó el incremento de las reservas internacionales durante el período de la Conflagración. La posición del país Aliado con Colombia se enmarca dentro del esquema del Buen Vecino, acto de la diplomacia al cual correspondimos convirtiéndonos en una fuente confiable de materias primas para suministrar a los Estados Unidos (Bushnell, 1984, 128-140).

Para el desarrollo de la agricultura moderna se creó la Oficina Panamericana del Café. Con el estallido de la Guerra, se suscribieron convenios comerciales cuyo objetivo consistía en regularizar el suministro del café a Estados Unidos, mediante el ejercicio de un pacto de cuotas de exportación, sujeto a precios convenidos y estables. El Acuerdo Interamericano del Café creado para regular el mercado cafetero se reconoció mediante el Acta No 29 de 1940 del Comité Nacional del Café, permitiendo que el Gerente de la Federación adquiriera el estatus diplomático, lo que le permitiría negociar en el exterior el café, y financiar con recursos de diversa procedencia las retenciones y almacenamiento del grano (Bates, 199, 126). A la cuenta pública del Fondo del Café se le unieron otras agencias del estado especializadas en promover el desarrollo económico ${ }^{8}$.

Durante la Guerra Mundial, al tema de la industrialización se le asignó el objetivo político de convertirse en un elemento para combatir el subdesarrollo. Aquel nuevo concepto se le encontró por primera vez en las obras del economista centro-europeo Paul Rosenstein-Rodan, quien en su trabajo sostuvo que para cubrir las necesidades del consumo local, de los países afectados por la Guerra, se necesitaba ubicar la mano de obra, aprovechando la posibilidad de crear empresas manufactureras. Las firmas, apoyadas en los encadenamientos productivos, y mediante acuerdos comerciales con los proveedores, podrían impulsar el avance de otras actividades complementarias (1943 y 1971, 245).

8. Para organizar el mercado de productores se creó primero la Federación Nacional de Cafeteros en 1927, y a fin de regular el mercado de consumidores se dispuso en 1940 del Fondo Nacional del Café, al cual se le dotó con recursos impositivos como fue el dólar cafetero, el Impuesto ad-valorem y años más tarde el de la Retención Cafetera. El mercado del petróleo y la actividad de la exploración se organizó con base en la actividad de La Empresa Colombiana de Petróleos-ECOPETROL, organismo que se fortaleció financieramente apoyándose en nuevos tributos y adoptando el dólar petrolero. Con la creación del Instituto de Fomento Industrial, se profundizó la sustitución de importaciones, mediante la promoción de industrias que produjeran insumos para la industria, y se estimulara la creación de bienes de capital. En el ámbito de las relaciones comerciales internacionales, se introdujeron importantes mecanismos de promoción del comercio, tendientes a regular el intercambio entre países amigos y vecinos, con los cuales se suscribirían años más adelante, convenios como fue el caso del Acuerdo de Cartagena y el ingreso de Colombia al GATT. 
La nueva fase del desarrollo entendida como la estrategia que asigna racionalmente los recursos provenientes del ahorro externo acumulado durante los años de la Segunda Guerra, se convierte en una acción económica racional que profundiza el proceso de Sustitución de Importaciones, y de promoción de la Diversificación Industrial. Su formulación no estuvo exenta de discusión, ya que se surgieron varias propuestas inspiradas en los trabajos de Lauchlin Currie y Albert Hirschman, autores cuya producción intelectual es copiosa como se observa en las referencias de pie de página. Currie quien dirigió La Misión del Banco de Reconstrucción y Fomento-BIRF, invitó a una reorganización de las finanzas públicas en favor de la inversión en la infraestructura, y la profundización de las actividades productivas de la agricultura y la industria. En el "Programa de Fomento para Colombia" se sugiere cómo invertir los recursos del Estado, siguiendo el modelo de Programas y Proyectos que inspiró el modelo de desarrollo del Valle del Tennessee ${ }^{9}$.

9. En el Archivo Lauchlin Currie de la Biblioteca Luis Angel Arango-BLA, se encuentran microfilmadas las obras completas que incluyen artículos, reportes, correspondencia y anotaciones personales, sobre materiales originales en los aspectos económicos, sociales y políticos que muestran como progresó Colombia luego de adoptarse las estrategias de la Planeación Económica. Destacamos por su significado testimonial "Fuentes, Factores y Políticas de Crecimiento Económico. Contrato FNR-647, Diciembre de 1989 y “Productivity, Growth and Distribution". Enero 13, 1989. Algunos de los trabajos inéditos son:

- CURRIE, Lauchlin. Typology of Industrial Development.

- CURRIE, Lauchlin. Teoría Macroeconómica y políticas de crecimiento. Contrato Fonade. FNR-698. Diciembre de 1990.

- $\quad$ CURRIE, Lauchlin. Chapter 1. Introduction Theory and Policy- Revisado Octubre 18 de 1990. GR 171.901016.

- CURRIE, Lauchlin. Bases de un programa de Fomento para Colombia. Informe de una Misión. 2 ed. Bogotá: Banco de la República, 1951. p. 348.

- CURRIE, Lauchlin. The Exchange Constraint on Development-A Partial Solution to the Problem. En: The Economic Journal, December, 1971, vol. 81, no. 324, p. 886-903.

- $\quad$ CURRIE, Lauchlin. Theory and Policy. En: A Note on Productivity and Growth. July 9, 1990.

- CURRIE, Lauchlin. Desarrollo Económico Acelerado. La Necesidad y los Medios. México: Fondo de Cultura EConómica, 1968.

- CURRIE, Lauchlin. Ahorro, Corrección Monetaria y Construcción. Ensayos Sobre Interrelaciones en Colombia. Bogotá: Universidad de las Andes, 1974.

- CURRIE, Lauchlin. La Política Urbana en un Marco Macreconómico. Banco Central Hipotecario 50 Años. Bogotá.: s.n, 1982.

- CURRIE, Lauchlin. Políticas de Crecimiento y Desarrollo. Una Selección de Escritos de los Ultimos Años. Bogotá:, S.n., 1982.

- CURRIE, Lauchlin. Evaluación de la Asesoría Económica a los Países en Desarrollo. El Caso Colombiano. Fondo Editorial-CEREC, 1984.

- CURRIE, Lauchlin. Fuentes, Factores y Políticas de Crecimiento Económico. En: Contrato FNR-647. Diciembre, 1989.

- $\quad$ CURRIE, Lauchlin. Further Implications of Endogenous Growth. October 2, 1990.

- CURRIE, Lauchlin. Productivity, Growth and Distribution: Conceptual Relationships. [Manuscrito] Enero 13, 1989. En: Archivo Lauchlin Currie.Biblioteca Luis Angel Arango. Rollo 7. Continuación R.4 A.

- $\quad$ CURRIE, Lauchlin. The Neoclassical Theory of Growth. Nov 2, 1990. Cap. 6.

- CURRRIE, Lauchlin. Guidelines for a New Strategy. The National Planning. Bogotá: s.n. 1972.

- CURRIE, Lauchlin. National Planning in a Developing Economy. Cámara de Comercio Colombo Americana- July 29,1971 
En los trabajos de Hirschman, publicados bajo los títulos "The Strategy of Economic Development"10 y "Journeys Toward Progress"11 se relatan aspectos relacionados con el apoyo a la política de desarrollo seguida en Colombia, para promover el desarrollo industrial y vincular parte de los recursos que se generaban con la actividad exportadora del café y nuevos productos de exportación provenientes del sector manufacturero. Nicholas Kaldor $(1986,190)$ sugería que la industrialización era un proceso acumulativo, en el que el desarrollo de las industrias productoras de bienes de consumo, precedía a la producción de bienes de capital, idea que abrió en el mundo una nueva esperanza para el desarrollo.

\section{TERCER CICLO 1958-1989.}

Primera Fase. 1958-1975.

La acogida de los nuevos Planes y Proyectos de Desarrollo, propuestos por el Presidente de la República con la ayuda del Departamento de Planeación Nacional, permitió racionalizar el proceso de asignación de los recursos de ahorro nacional en proyectos de infraestructura básica, que ayudaron a mejorar los programas sociales, extender los servicios públicos y de infraestructura básica con lo cual ayudó al desarrollo de las economías regionales y municipales. Con la acumulación de capital, se pudo avanzar en la reconversión industrial mediante el avance y difusión del conocimiento técnico, tanto en actividades complementarias de la industria básica, como en programas que mejoraron la competitividad sectorial. Dichas mejoras se lograron con la ayuda de organismos como el Instituto de Fomento Industrial -IFI, entidad encargada de promover la creación de industrias básicas especializadas en la producción de insumos químicos y proyectos que impulsaron la industria ensambladora. Gracias al desarrollo de la actividad crediticia, y con el apoyo del mercado de capitales, se financió y diversificó la base de la industria manufacturera. El marco institucional de esta política de modernización se enmarcó con la propuesta del "Plan Decenal de Desarrollo" aprobado durante el Gobierno de Alberto Lleras Camargo (1958-1962), el cual fijó como objetivo la profundización de la etapa de Sustitución de Importaciones.

Con base en el mayor nivel del capital acumulado desde la Guerra, y el aprovechamiento del creciente nivel de utilidades obtenidas por las industrias sustitutivas, se mejoró la eficiencia productiva, y gracias a la innovación aportada por los nuevos empresarios que tenían buen sentido gerencial se pudo ampliar la capacidad de la planta productiva. Gracias a la ayuda financiera internacional aportada por el programa de desarrollo de la Alianza para el Progreso,

10. HIRSCHMAN, Albert O. The Strategy of Economic Development. New Haven: Yale University Press, 1958.

11. HIRSCHMAN, Albert O. National Power and the Structure of Foreign Trade. University of California Press, 1945. Translated into Spanish. Journeys Toward Progress: Studies of Economic Policy-Making in Latin America. Twentieth Century Fund, 1963. 
y las estrategias de la AID, fue posible atender en momentos de escasez de divisas las importaciones de materias primas y equipos para lograr una mayor diversificación sectorial de la producción.

Durante esta primera fase del tercer ciclo de la economía exportadora, se pudo equilibrar el ritmo de las importaciones, al menos hasta el año de 1958, cuando se presentó una fase descendente del ciclo al caer los precios mundiales del café al terminar la Guerra de Corea. Esta situación coyuntural, de menores ingresos por concepto de las exportaciones del grano, significó una restricción cambiaria que obligó a las autoridades a estimular una política selectiva y racional de importaciones. La política arancelaria durante esta fase declinante de la economía, cumplía la doble función de proteger a la industria nacional frente a la competencia internacional y mejorar el nivel de recaudos a las arcas de la tesorería nacional. En esta nueva fase de estrechez, las autoridades y los grupos vinculados a la producción establecieron reformas institucionales con el objeto de impulsar las exportaciones y recuperar mercado. En cuanto al mercado de exportaciones de café, con la aprobación del Acuerdo Internacional del Café en Londres, se pudo organizar de nuevo el mercado, al racionalizar las siembras y promover la diversificación cafetera. A partir del año de 1959, mediante la Ley 1ạ, y luego en 1967 cuando se expide el DecretoLey 444 de 1967, el Presidente Lleras Restrepo lanzó un nuevo Plan de Promoción del Comercio y de apertura de mercados. Con el apoyo de diversos Acuerdos Comerciales entre el país y zonas geográficas comerciales se diversificó la gestión comercial del país. Para tal efecto, se crearon organizaciones como el Fondo de Promoción de Exportaciones -Proexpo, el Instituto de Comercio Exterior -Incomex, con su Junta de Importaciones, y mecanismos económicos como la licencia global, el Certificado de Abono Tributario-C.A.T, y el Plan Vallejo.

En el Banco de la República se organizó la Junta Monetaria con el objeto de racionalizar el crédito y encauzar la política cambiaria. En el ámbito del desarrollo con la apertura de cuentas financieras para el desarrollo de crearon los Fondos Financieros del sector Agropecuario, Industrial, de Desarrollo Urbano y Eléctrico. Gracias a la disposición de recursos de redescuento se pudo financiar al Fondo de Promoción de Exportaciones -Proexpo, con el cual se preparó el país para competir en el exterior.

Segunda Fase. 1975-1989.

Los nuevos acontecimientos históricos que se presentaron en el mundo con ocasión de la crisis del dólar ocurrida en el año de 1971, cuando se interrumpió la convertibilidad del dólar por oro, y cuatro años más tarde cuando sobrevino la crisis mundial del petróleo, afectó la capitalización de los países de la región. Colombia tuvo que renovar su política industrial para poder competir, pensando en ampliar el ámbito del mercado a la esfera internacional, y en defender a la economía local del efecto de las crisis. Fue durante el gobierno del Presidente Pastrana Borrero que las ideas del crecimiento desbalanceado propuestas por Lauchlin Currie se institucionalizan, y fue con base en el medio del ahorro privado que se movilizaron recursos para promover la 
actividad de la construcción de vivienda. El público, al responder con su ahorro al Sistema de Poder Adquisitivo Constante -Upac, estimuló la actividad de los encadenamientos industriales asociados con la industria de la construcción. La obra de Currie consignada en archivo personal es extensísima, y fue altamente reconocida para el desarrollo nacional. Fue una respuesta eficaz al "Foreign Exchange Constraint" que retardaba el crecimiento ${ }^{12}$.

Con el surgimiento de organizaciones como la Organización Internacional del Café -OIC y la Asociación de Países Productores de Petróleo -APEP, se planteó la posibilidad de intervenir los mercados mundiales de bienes básicos, con el propósito de restaurar el poder de compra perdido por las materias primas. Esta expresión de la política exterior, no estuvo exenta de críticas ya que en los países importadores se argumentaba que esta situación de precios altos llevaría al mundo a experimentar un estado de sobre-producción, que a la postre arrastraría a la ruina a los países exportadores de productos básicos. En virtud del aumento de los ingresos en moneda extranjera, y de la ampliación de la base productiva de productos como el petróleo en el mundo, el crédito extendido a los países del tercer mundo elevó de manera peligrosa el nivel máximo de endeudamiento de estos países. La deuda internacional de América Latina se elevó en cuantía superior a los US\$117 mil millones de dólares, con lo cual se precipitó en la región la Crisis de la Deuda Externa a mediados de los años ochenta. Con las declaraciones de Cartagena, Montevideo y Mar del Plata de 1985 y 1986, los países latinoamericanos guiados por un claro sentimiento político, e inspirados por la mente imaginativa del Ministro de Relaciones Exteriores del Uruguay, el Contador Enrique Iglesias, se declaró por parte de los países signatarios del Consenso de Cartagena, la necesidad de politizar el suceso histórico de la Deuda Externa Latinoamericana.

Esta circunstancia insostenible, llevó a los países acreedores a ponerse de acuerdo con los deudores, al acordar una reducción y unificación de los tipos de interés, ampliación del período de gracia para reiniciar los pagos de la deuda, extensión del plazo para el servicio total de la deuda, y disposición de recursos adicionales por parte de la banca multilateral. Este sentimiento social, descrito por los profesores Luís Jorge Garay y Ricardo Ffrench Davies, muestra la manera particular como cada uno de ellos se adaptó al cambio, y cómo se adquirieron compromisos para respetar el código de conducta que distinguía entre temas financieros y económicos. Se impidió que la Banca Central financiara con recursos de emisión las necesidades particulares de los gobiernos, evitando con ello financiar gastos como los de la nómina de las empresas deficitarias.

12. Su obra más importante fue publicada en el Economic Journal bajo el título "The Exchange Constraint on Development. A Partial Solution to the Problem. A Comment", 1971 y comentada en el mismo Journal por Gustav Ranis en Marzo de 1973. Sostiene Ranis que el sector de la vivienda, se constituiría en "no other item of consumption to offer such effective demand possibilities" y que debido a su alta relación capital-producto "where explicitly Currie denies that underemployment problems are Keynesian in character" justifica la urgencia de aprovechar para el desarrollo las fuentes de capital existentes para superar el escollo del subempleo y subutilización de recursos escasos de ahorro. 


\section{CONCLUSIÓN Y EL NUEVO CICLO DE LA GLOBALIZACIÓN 1989-2010}

El "cuarto" ciclo, se inicia con la caída del Muro de Berlín en el año de 1989, hecho sobresaliente de la historia política reciente. Sugiere el final de la Guerra Fría, y determina para los países en desarrollo, ingresar a un modelo de mercado en su concepción más libre. Se le conoce como la fase de la globalización. Consecuencia de este fenómeno histórico es el inicio de un "cuarto ciclo" del desarrollo, dentro de cuya característica principal sobresale la apertura de los mercados en un medio económico, en que el Estado abandona el proceso de desarrollo, y en el cual las empresas multinacionales actúan como un nuevo agente de la acumulación, la distribución y la responsabilidad social.

La función tradicional de promover la acumulación del capital por la vía de la movilización exógena de los factores productivos, evolucionó por una posición más libre, en la cual al Estado se le reclama el no haber sido eficiente en la asignación del ahorro, razón por la cual abandona su papel protagónico como inversionista y como gestor de proyectos económicos. En síntesis, el Estado deja de movilizar recursos de ahorro público hacia la promoción de la producción, y gradualmente se transforma en el agente regulador y agente vigilante de la actividad económica.

En respuesta a esta situación de inestabilidad cambiaria y de comercio exterior, durante la década de 1990, cuando comienza la quinta fase del ciclo económico en estudio, se abre el mercado a los dictados de la globalización, cuando más de treinta países en desarrollo incluyendo los latinoamericanos, acogieron las ideas que inspiraron el Consenso de Washington, iniciativa que justifica el pensamiento liberal de la época, y que tiene por objeto permitir que los mercados funcionen libremente de acuerdo a las reglas que dictan los mercados y no los Estados. Esta profunda reforma liberal de corte mercantil, apoyó los procesos de industrialización a través del respeto de los postulados de la competitividad económica, situación que no se registraba en el continente desde la Gran Depresión.

Con la adopción del modelo del Consenso de Washington, se adopta una reforma del Estado que otorga autonomía a las regiones, y se independiza el Banco de la República de la política macroeconómica ejercida por el Estado. Termina así la estrategia gubernamental de la Sustitución de Importaciones, en la que el estado apoyó al desarrollo del sector, y a los cafeteros se les exime de los impuestos al comercio exterior, luego de haber fortalecido el Fondo Nacional del Café. Se propusieron también otras alternativas de política económica orientadas a racionalizar el mercado, dentro de las que sobresale la liberación de los tipos de interés en el ámbito crediticio, se flota el tipo de cambio al someterlo a la fuerzas del mercado, en un momento en que el petróleo y los minerales se convierten en factores dinámicos del comercio exterior, se eliminó gradualmente la intervención de los precios en el mercado de bienes esenciales, y terminaron las políticas de sustentación de precios atribuidos a algunos productos de consumo básico. Se busca con el nuevo modelo, competir con precios de equilibrio en 
los mercados mundiales a través de una tasa de cambio libre, tramitando en el Congreso las Leyes $7^{\underline{a}}$ y $9 \underline{a}$ de 1991.

La eliminación de las barreras a la inversión e ingreso de capitales genera un auge sin precedentes en las corrientes de inversión directa y de intercambio a escala regional al acogerse modelos de libre comercio como en los casos del ALCA, y los TLC's con Estados Unidos, Canadá y Europa, entre otros.

Gradualmente, y durante esta nueva fase del desarrollo, el Estado se transforma en un agenteregulador, y su nuevo objeto económico se identifica con custodiar al sector privado para que se comprometa en adelantar las obras identificadas como alternativas socialmente productivas. Técnicamente, se trata de buscar en las iniciativas públicas un esquema financiero en el cual, el costo de oportunidad del dinero determine fórmulas para involucrar en la inversión el beneficio social de un proyecto de rendimiento público.

En este naciente contexto de mercados abiertos a la inversión, disponibilidad al acceso de bienes y de capitales, conocimiento y tecnología, se avanza hacia la integración de los mercados mundiales, al tratar de convertirlo en uno solo. El sistema financiero internacional, y la estructura del comercio y el flujo de la inversión extranjera, descentraliza sus decisiones, y la localización de las empresas en el mundo la determinan una nueva lógica como lo estudia el economista Dunning $(1999,13)$.

Durante esta fase del ciclo económico, se estimuló el avance de la actividad extractiva, dentro de las que merecen especial mención la minería del níquel, el carbón térmico y coquizable, la industria extractiva de los hidrocarburos y el gas. En este nuevo medio global:

[...] el mercado mundial del café se constituye en un importante negocio cuya cadena productiva reporta ingresos de cerca de $\$ 130$ billones. Los productores mundiales solo reciben US\$ 17 billones por concepto de las ventas internacionales del café verde en el año 2006 (Stiglitz, 2006)

Para acceder al nuevo "sistema transforamdor global" caracterizado por la fragmentación del proceso productivo, formando cadenas de valor que se entrelazan y trascienden las fronteras políticas territoriales, se propone en el nuevo medio de la globalización, estructurar estrategias de negociación internacional, que permitan acceder a los beneficios de la cadena mundial de valor. Hoy en día los países exportadores de café que participan tan solo de una sexta parte del valor generado por la industria transformadora mundial, lo podrían hacer en una mayor proporción. Ganar solo el diez por ciento de estos eslabones de la cadena internacional, equivale a duplicar las ventas del café sin elaborar, vendido por parte de los países productores. 


\section{BIBLIOGRAFÍA}

\section{Material sin Publicar en Archivos Británicos.}

PUBLIC RECORD OFFICE-P.R.O. Londres. En adelante P.R.O. Foreign Office London. F.O. 371. Volúmenes de 1927 a 1935.

F.O. 420. Volúmenes de 1924 a 1935.

F.O. 369. Volúmenes de 1927 a 1930.

P.R.O. FO-361-15086. Mensaje Presidencial al Congreso. 20 de julio de 1931.

P.R.O. FO 361- 16513-366/ A495 / 1068 / 11. Reporte Anual de Colombia 1932.

De

Dickson a Sir John Simon.

P.R.O. FO- 361-15083 / A16 / 11.

P.R.O. FO-361-15832-369 / A4233 / 18 / 11.

\section{CAFÉ}

- Abella Gómez, Mauricio. (2002). Hacienda Pública, Moneda y Café. El Papel Protagónico de Alfonso Palacio Rudas. Bogotá. Federación Nacional de Cafeteros y Banco de la República.

- Bejarano, Jesús Antonio. (1987). Ensayos de Historia Agraria Colombiana. Cerec. Bogotá.

- Bejarano, Jesús Antonio. (1994). Historia Económica y Desarrollo. La Historiografía Económica sobre los Siglos XIX y XX en Colombia. Bogotá. CEREC.

- Beyer, Robert Carlyle. (1947). The Colombian Coffee Industry. Origins and Major Trends, 1740-1940. University of Minnesota. Ph. D.

- Cuellar, Fidel H. (2004). El Crédito Cafetero en Colombia. Economía Instituciones y Política. 1920-2002. Bogotá. Universidad Nacional de Colombia. Ediciones Uniandes.

- Echavarría, Juan José. (1999). Crisis e Industrialización. Las Lecciones de los Treinta. Bogotá. TM Editores. Banco de la República y Fedesarrollo.

- Junguito Bonnet, Roberto. (1978). Economía Colombiana Cafetera. Bogotá. Fondo Cultural Cafetero.

- Koffman, Benett. E., 81967). The National Federation of Coffee Growers of Colombia. California University. Tesis de Ph. D.

- Mc Greevey, William Paul. (1971). An Economic History of Colombia. Cambridge. Cambridge University Press. Cambridge. 
- Montenegro, Armando. (1993). Café, Dinero y Microeconomía en Colombia. Ensayos. Bogotá. Fescol. Tercer Mundo.

- $\quad$ Nieto Arteta, Luis Eduardo. (1973). Economía y Cultura en la Historia de Colombia. Bogotá. Editorial Oveja Negra.

- $\quad$ Nieto Arteta, Luis Eduardo. (2001). El Café en la Sociedad Colombiana. El Ancora Editores. Bogotá.

- Palacios, Marco. (2002). El Café en Colombia. 1850-1970. Una Historia Económica, social y Política. Tercera Edición. Planeta. Bogotá.

- Parsons, James J. (1968). Antioqueño Colonization in Western Colombia. University of California. Los Angeles.

- Parsons, James J. (1997). La Colonización Antioqueña en el Occidente de Colombiana. Banco de la República. El Ancora Editores. Bogotá.

- Pizano Diego. (2001). El Café en la Encrucijada. Bogotá. Alfaomega. Cambio.

- $\quad$ Rosenstein-Rodan, Paul N. "Problems of Industrialization of Eastern and Southt-Eastern Europe". En: The Economic Journal. June-September, (1943), vol. 53, p. 202-211. Reimpreso en: AGARAWLA, A.N. y SINGH, S.P. En: The Economics of Underdevelopment. 1973, Oxford: Oxford University Press, p. 245.

\section{TEMAS COLOMBIANOS}

- Beyer, Robert Carlyle. The Colombian Coffee Industry Origins and Major Trends, 17401940. University of Minnesota. Ph D. (1947). Apéndice Cuadros I y IV.

- Currie, Lauchlin. (1951). "Bases de un Programa de Fomento para Colombia", Informe de una Misión. Segunda Edición. Banco de la República. Bogotá, 1951, pág. 348.

- Currie, Lauchlin. "The Exchange Constraint on Development. A Partial Solution to the Problem. A Comment". Economic Journal. (1973). Vol 83. Respuesta alos comentarios del profesor Gusatv Ranis.

- Currie, Lauchlin. "The Exchange Constraint on Development-A Partial Solution to the Problem". En: The Economic Journal, December, (1971), vol. 81, no. 324, p. 886-903 
- Currie, Lauchlin. (1971). "The Exchange Constraint on Development. A Partial Solution to the Problem. A Comment", Economic Journal. Este trabajo fue comentado por Gustav Ranis en el Economic Journal de Marzo de 1973

- Echavarría, Enrique. (1943). Historia de los Textiles en Antioquia. Medellín. Editorial Bedout.

- Franco Holguín, Jorge. (1966). Evolución de las Instituciones Financieras en Colombia. México. Gráfica Panamericana.

- Gómez Martínez, Fernando y Arturo Puerta. (1945). Biografía Económica de las Industrias de Antioquia. Medellín. Tipografía Bedout.

- Greco. Banco de la República. (2002). El Crecimiento Económico Colombiano en el Siglo XX. Director Miguel Urrutia Montoya. Fondo de Cultura Económica. Bogotá.

- Hirschman, Albert O. (1958). The Strategy of Economic Development. New Haven: Yale University Press, 1958.

- Hirschman, Albert O. (1963). National Power and the Structure of Foreign Trade. University of California Press, 1945. Traducido al Español en Journeys Toward Progress: "Studies of Economic Policy-Making in Latin America". Twentieth Century Fund, 1963.

- Lleras De La Fuente, Fernando. El Café, Antecedentes Generales y Expansión hasta 1914. Tesis de Grado. Uniandes, (1970). Cuadro 6.

\section{DESARROLLO ECONÓMICO.}

- Blaug, Mark. (1997). The Methodology of Economics. Or How the Economist Explain.Cambridge. Cambridge University Press. Second Edition.

- Braudel, Fernand. (1976). The Mediterranean and the Mediterranean World in the Age of Philipll. Great Britain. Fontana.

- Chenery, Hollis B. "Patterns of Industrial Growth", American Economic Review, September (1968), pp. 637-8.

- Cipolla, Carlo M. (1991). Entre la Historia y la Economía. Introducción a la Historia Económica. Barcelona. Editorial Crítica.

- Dunning, John H. (1999). Governments, Globalization, and International Business. Oxford, Oxford University Press. 
- $\quad$ Friedman, Milton. (1953). "On the Methodology of Positive Economics" Tomada de Essays in Positive Economics. Oxford. Oxford University Press. Págs, 3-43.

- Gemelli. Giulianna. (2005). Fernand Braudel. Valencia. Universitat deValencia. Universidad de Granada.

- Green, William A. (1995). "Periodizing World History". History and Theory, vol.34, No. 2, Theme Issue 34: World Historians and Their Critics. Mayo, pp. 99-111.

- Kaldor, Nicholas Kaldor. (1986). "Limits on Growth". Oxford Economic Papers". Vol 38. pp. 187-198

- Klenow, Peter J y RODRIGUEZ-CLARE Andrés. (2005). "Externalities and Growth", Handbook of Economic Growth, Volumen 1 A. Editado por Philippe Aghion y Steven N. Durlauf. Elsiver. B.V.

- Lewer, Joshua J. y Hendrik VAN DEN BERG. (2003). "How Large is International Trade's Effect on Economic Growth?" Journal of Economic Surveys. Vol. 17, No 3. pp, 363-396.

- $\quad$ Maizels, Alfred, L.F. Campbell-Boross y P.B.W. Rayment. (1971). Exports and Economic Growth of Developing Countries. Cambridge. Cambridge University Press.

- Porter, Michael. (1995). Ventaja Competitiva. Creación de Valor y Sostenimiento de un Desempeño Superior. México. Editorial Continental.

- $\quad$ Rosenstein-Rodan, Paul N. "Problems of Industrialization of Eastern and Southt-Eastern Europe". En: The Economic Journal. June-September, (1943), vol. 53, p. 202-211. Reimpreso en: AGARAWLA, A.N. y SINGH, S.P. En: The Economics of Underdevelopment. 1973, Oxford: Oxford University Press, p. 245.

- $\quad$ Stiglitz, Joseph. "It Takes More than Free Trade to End Poverty Mandelson Treats the Negotiations With Impoverished African Countries as a Bargain Between Equals". February 3, (2006). Tomado en Octubre de 2010. http://www.globalpolicy.org/socecon/bwi-wto/ wto/2006/0203stiglitz.htm. 